\title{
Traumatic spine injury in Kashan, Iran
}

\section{Esmaeil Fakharian', Zahra Sehat ${ }^{2 *}$, Mojtaba Sehat ${ }^{2}$}

'Department of Neurosurgery, Trauma Research Center, Kashan University of Medical Sciences, Kashan, Iran ${ }^{2}$ Trauma Research Center, Kashan University of Medical Sciences, Kashan, Iran

Received: 13 April 2019
Accepted: 19 May 2019
Published online: 28 May 2019
*Corresponding author: Zahra
Sehat, Trauma Research Center,
Kashan University of Medical
Sciences, Ghotb-e-Ravandi Blvd.,
Kashan, Iran.
Email: sehat.zahra426@gmail.com
Competing interests: None.
Funding information: None.
Citation: Fakharian E, Sehat Z, Sehat
M. Traumatic spine injury in Kashan,
Iran. Journal of Emergency Practice
and Trauma 2019; 5(2): $65-70$. doi:
10.15171/jept.2019.12.

\begin{abstract}
Objective: Traumatic spine injuries are seriously important and are associated with considerable morbidity and mortality. The goal of this study is to determine the epidemiology of the traumatic spine injuries in Shahid Beheshti Hospital of Kashan University of Medical Sciences (KAUMS), the main trauma center in Kashan, Iran.

Methods: This cross-sectional study was undertaken on all cases of traumatic spinal injuries that were admitted to Shahid Beheshti hospital of KAUMS from 2014 to 2017. A checklist was used to collect demographic characteristics (age, gender, education, marital) and mechanism of the injury of the spine. According to ICD-10, the level of the injury was detected by diagnostic tests such as radiologic imaging and magnetic resonance imaging and computed tomography scans, and also multi-trauma final outcome of the patients with traumatic spine injury (TSI) and rate of the spinal cord injury (SCl), hospital length of stay and surgery treatment was investigated.

Results: The number of patients with traumatic spine injuries was 986. Among this batch $77 \%$ were males. The mean age of the patients was 39.5 years. Most injuries occurred in the age group of 15 to 30 years. Traffic accident was the most common mechanism of the trauma (35.2\%) followed by the falls (26.95\%) motorcycle accident (17.9\%), assault by a sharp object or an unspecified object $(10.13 \%)$ and other reasons $(5.6 \%)$. The most common site of injury was in lumbar section (24.41\%). Patients with traffic accident injury had the longest hospitalization. The rate of $\mathrm{SCl}$ was $2.63 \%$ and the rate of mortality was $2.3 \%$.

Conclusion: The TSI is an important and serious public health problem and a major cause of disability. Understanding the epidemiology can help us contrive appropriate preventative measures.

Keywords: Epidemiology, Iran, Kashan, Traumatic Spine Injury
\end{abstract}

\section{Introduction}

Traumatic spine injury (TSI) is a common cause of disability. This injury can result in long-term disability and death (1). Traumatic spine injuries can occur as an isolated lesion or in association with other organ injuries (2). The incidence rate of TSI in Iran is 16.35 per 100000 people. Similar to other types of traumatic injury, the incidence of traumatic spine fracture in males is more than females (1). Also, the prevalence of traumatic spinal cord injury (SCI) in Iran ranges from 1.2 to 11.4 per 10000 people (3). The global incidence of SCI varies from 8.0 to 246.0 cases per million inhabitants per year. In addition to the regional differences regarding the prevalence rates of SCI across the globe, there has been an upward trend concerning the prevalence rates over the last decades (4).

The regional differences in the patterns and causes of injuries have significant implications for prevention policies. The prevention policies should be based on available regional data in order to make important decisions (5). The incidence of TSI increases in old population $(6,7)$. This is mainly young people who may increase the burden of the disease (8). Understanding the epidemiology of TSI is essential to plan for cost-effective care and develop preventive strategies (6).

The purpose of this study is to describe the epidemiology of TSI among patients admitted to Shahid Beheshti Hospital of Kashan University of Medical Sciences (KAUMS). We designed a cross-sectional study to determine the incidence, the demographics, and etiology associated with injuries and final outcomes. The results of this study can identify the key opportunities for advancement in the decrease burden of TSI, cost-effective of prevention and treatment of TSI.

\section{Methods}

In this cross-sectional study, we used the data of patients $(\mathrm{n}=986)$ with TSI admitted to Shahid Beheshti hospital of KAUMS (from 2014 to 2017). The administrative dataset of Shahid Beheshti hospital was used for this purpose. Medical records of patients with spinal trauma were 
obtained from the Medical Records Department of the hospital. All patients' data remained confidential during the study.

Shahid Beheshti hospital is a referral teaching hospital in Kashan. Kashan is a city located in the central part of the Islamic republic of Iran with a population of about 500000 and is among the crowded cities of Iran (9). This hospital is a trauma center which admits injured patients.

We used a checklist to gather data. The checklist included demographic characteristics (age, gender, education, marital) and mechanism of injury according to ICD-10. In addition, it contained other information concerning the level of injury detected by diagnostic tests (radiologic imaging, magnetic resonance imaging and computed tomography scans), multi-trauma, final outcome of the patients with TSI, the rate of SCI, hospital length of stay and surgery treatment. Regarding the reliability of this checklist, we used Cronbach Alpha to estimate the reliability (Cronbach alpha $=0.76)$. The statistical analysis (chi-square in order to investigating the relationship between variables) was conducted using SPSS software version 19 (SPSS Inc., Illinois, USA). $P<0.05$ was considered as the level of significance. All information about patients remained confidential during the study period.

\section{Results}

The total number of patients with TSI was 986 in which $77 \%$ of them were males $(n=759)$ and $23 \%$ were females

Table 1. Categorization of age based on sex

\begin{tabular}{|c|c|c|c|}
\hline \multirow{2}{*}{ Age-group } & \multicolumn{2}{|c|}{ Sex } & \multirow{2}{*}{ Total (\%) } \\
\hline & Man & Woman & \\
\hline $1-5$ & 9 & 3 & $12(1.21)$ \\
\hline $5-15$ & 36 & 14 & $55(5.58)$ \\
\hline $15-30$ & 277 & 24 & $301(30.1)$ \\
\hline $30-45$ & 204 & 54 & $258(25.2)$ \\
\hline $45-60$ & 143 & 34 & $177(17.3)$ \\
\hline $60-75$ & 61 & 30 & $91(9.84)$ \\
\hline $75-95$ & 26 & 22 & $48(4.7)$ \\
\hline Total & 759 & 227 & 986 \\
\hline
\end{tabular}

$P<0.004$. $(\mathrm{n}=227)$. The mean age of patients was $39.05(\mathrm{SD}=0.58)$ with a median of 35 years (the minimum age of patients was 2 and the maximum age was 95). The most frequent of these injuries occurred in the age group of 15 to 30 years $(P<0.004)$.

Most patients had the education level under diploma (n $=621(63 \%)$ and $16 \%$ of them had a university education $(\mathrm{n}=159)$. About $33 \%$ of patients with TSI were married $(n=325)$. Table 1 shows the categorization of age among patients. For analysis of this data, we used chi-square test. In occupational survey dealing with job of patients with TSI, most patients were workers $(27.35 \%, \mathrm{n}=270)$, unemployed $(25.53 \%, \mathrm{n}=252)$, housewives $(16.21 \%, \mathrm{n}=$ $160)$ or students $(17.73 \%, \mathrm{n}=175)$. Others had another job or their jobs were not specified. The majority of traumatic spine injuries happened in spring and summer. Also, $76.9 \%$ of all injury been have happened between Late spring until the end of September $(P<0.001)$.

The mechanisms of injuries are described as follows: car occupant injured in a traffic accident was the most common mechanism of trauma $(35.2 \%, \mathrm{n}=349)$, followed by the falls accident $(26.95 \%, \mathrm{n}=266)$, motorcycle rider injured in a traffic accident $(17.9 \%, \mathrm{n}=177)$, assault by a sharp object or an unspecified object $(10.13 \%, \mathrm{n}$ $=100)$, and other reasons $(5.6 \%, \mathrm{n}=50) .(P=0.075)$. The mechanisms of injuries in different age groups are presented in Table 2.

Among patients with TSI ( $\mathrm{n}=987), 30.49 \%(\mathrm{n}=301)$ of them had multi-trauma and head injuries were the most common $(5.34 \% ; n=53)$. This type of injury was the most frequent among other traumatic injuries leading to hospitalization.

Traumatic spine injuries are categorized into four anatomic regions including cervical, thoracic, lumbar and thoracolumbar. As depicted in Table 3, in our study the most common injury occurred in lumbar section (24.41\%; $\mathrm{n}=241$ ). Patients whit Traumatic spine injuries mostly involved of fracture of lumbar vertebra $23.7 \%(n=234)$ of total patients studied and 174 cases involved Cervical section injury $(17.62 \%)$. In addition, $21.27 \%(n=210)$ of cases had thoracic vertebra fracture. Sixty-one patients with TSI had thoracolumbar spine injury (6.18\%). Besides,

Table 2. Mechanisms of injuries in age groups

\begin{tabular}{|c|c|c|c|c|c|c|c|}
\hline & & \multicolumn{4}{|c|}{ Mechanism } & \multirow[b]{2}{*}{ Other } & \multirow{2}{*}{ Total } \\
\hline & & Car accident & Fall & Motorcycle & Assault & & \\
\hline \multirow{7}{*}{ Age group } & $1-5$ & 7 & 4 & 0 & 0 & 1 & 12 \\
\hline & $5-15$ & 23 & 16 & 7 & 2 & 7 & 55 \\
\hline & $15-30$ & 87 & 46 & 86 & 67 & 15 & 301 \\
\hline & $30-45$ & 123 & 78 & 40 & 12 & 5 & 258 \\
\hline & $45-60$ & 65 & 60 & 32 & 12 & 8 & 177 \\
\hline & $60-75$ & 27 & 39 & 9 & 7 & 9 & 91 \\
\hline & $75-95$ & 17 & 23 & 3 & 0 & 5 & 48 \\
\hline Total & & 349 & 266 & 177 & 100 & 50 & 987 \\
\hline Percent & & $35.3 \%$ & $26.95 \%$ & $17.9 \%$ & $10.13 \%$ & $5.06 \%$ & $100.0 \%$ \\
\hline
\end{tabular}

$P=0.075$. 
Table 3. Level of traumatic spine Injury

\begin{tabular}{|c|c|c|c|c|c|}
\hline Spine injury & & No. & $\%$ & Total frequency & Total percent \\
\hline \multirow{5}{*}{ Cervical } & Unspecified injury of neck & 92 & 9.32 & \multirow{5}{*}{174} & \multirow{5}{*}{$17.62 \%$} \\
\hline & Dislocation of cervical vertebra & 13 & 1.31 & & \\
\hline & Cervical vertebra fracture & 19 & 1.92 & & \\
\hline & Injuries of cervical spinal cord & 16 & 1.62 & & \\
\hline & Fracture of neck, unspecified & 34 & 3.44 & & \\
\hline \multirow{9}{*}{ Thoracic } & Unspecified injury of thorax & 73 & 7.34 & \multirow{9}{*}{210} & \multirow{9}{*}{$21.27 \%$} \\
\hline & Fracture of thoracic vertebra & 78 & 7.9 & & \\
\hline & Superficial injury of other and unspecified parts of thorax & 5 & 5.2 & & \\
\hline & Multiple fractures of thoracic spine & 30 & 3.4 & & \\
\hline & Open wound of other parts of thorax & 3 & 0.30 & & \\
\hline & Fracture of other parts of thorax & 4 & 0.40 & & \\
\hline & Injury of spinal cord, level unspecified & 7 & 0.70 & & \\
\hline & Dislocation of shoulder joint & 4 & 0.40 & & \\
\hline & Fracture of clavicle & 6 & 0.60 & & \\
\hline \multirow{4}{*}{ Thoracolumbar } & Injury of spinal cord of thoracolumbar & 3 & 0.31 & \multirow{4}{*}{61} & \multirow{4}{*}{$6.18 \%$} \\
\hline & Fracture of rib & 49 & 4.9 & & \\
\hline & Injury of abdomen, lower back and pelvis & 8 & 0.82 & & \\
\hline & Other recurrent vertebral subluxation & 1 & 0.1 & & \\
\hline \multirow{3}{*}{ Lumbar } & Fracture of lumbar vertebra & 234 & 23.7 & \multirow{3}{*}{241} & \multirow{3}{*}{$24.41 \%$} \\
\hline & Fracture of ilium & 4 & 0.43 & & \\
\hline & Fracture of sacrum & 3 & 0.31 & & \\
\hline \multirow{8}{*}{ Multiple trauma } & Unspecified multiple injuries & 20 & 2.02 & \multirow{8}{*}{301} & \multirow{8}{*}{$30.49 \%$} \\
\hline & Fracture of skull and facial bones & 38 & 3.86 & & \\
\hline & Fracture of rib & 45 & 4.54 & & \\
\hline & Unspecified injury of head & 53 & 5.34 & & \\
\hline & Unspecified injuries of lung & 43 & 4.32 & & \\
\hline & Open wound of lower back and pelvis & 37 & 3.72 & & \\
\hline & Open wound of thorax, part unspecified & 38 & 3.82 & & \\
\hline & Open wound of abdominal wall & 27 & 2.73 & & \\
\hline
\end{tabular}

$53.9 \%$ of thoracolumbar spine fractures occurred due to fall and $47.3 \%$ occurred due to RTC.

In the current study, the rate of SCI was $2.63 \%(n=26)$ in which 7 cases had thoracic spinal cord, 16 cases had cervical spinal cord and 3 cases had thoracolumbar SCI. Seventeen cases of spinal cord injuries were due to road traffic accident (RTA) and 4 cases were due to falls and 3 cases result of other mechanisms.

The hospital length of stay for all patients with TSI in this study was different and dependent upon age, sex, mechanism and type of injury. Surgery operation had a significant role for hospital length of stay $(P=0.01)$. However, the median duration of hospital stay for all patients was 4 days $($ mean $=5.7$, minimum $=1$ and maximum $=157$ ).

Patients with traffic accident injury had the longest hospitalization and the second cause of hospital stay was related to injury due to fall and assault. Table 4 shows the duration of hospital stay for different mechanisms of TSI. Of all patients $(\mathrm{n}=987), 97.7 \%(\mathrm{n}=964)$ survived but $2.3 \%(n=23)$ died in hospital and two patients passed away later. Patients who sustained spine injury as a result of car accident had a significantly higher rate of death than those who were injured due to falling ( $1.5 \%$ vs $0.5 \%$, $P=0.04$ ) (Table 5).

Among the patients hospitalized due to TSI for more than 24 hours, 424 patients underwent surgery and their injury was owing to traffic accidents (128). The most common methods of surgery for these patients are shown in Table 6 .

\section{Discussion}

In this study, we aimed to determine the incidence and etiology of TSI in patients admitted to the referral hospital of Kashan. Findings reveal that the total number of patients with TSI from 2014 to 2017 was 987, and TSI mostly occurred in the age group of 15 to 30 years. Also, in all age groups, male injury (77\%) was more than female injury (23\%). Findings showed that $55.3 \%$ of patients with TSI were between 15 and 44 years (Table 1 ). This finding is consistent with the results of other studies conducted in Iran and other countries. A study conducted by Knutsdottir et al in Iceland over a period of 34 years 
Table 4. Duration of hospital stay for different mechanisms of traumatic spine injury

\begin{tabular}{|c|c|c|c|c|c|c|}
\hline & $1-4$ days & 4-10 days & 10-20 days & 20-30 days & $30-160$ days & Total \\
\hline Traffic accident & 137 & 69 & 34 & 2 & 7 & 249 \\
\hline Fall & 121 & 70 & 20 & 5 & 0 & 216 \\
\hline Motorcycle & 89 & 49 & 13 & 4 & 2 & 157 \\
\hline Assault & 77 & 14 & 6 & 0 & 0 & 97 \\
\hline Total & 424 & 202 & 73 & 11 & 9 & 719 \\
\hline
\end{tabular}

Table 5. Surgical treatment in any mechanism of injury

\begin{tabular}{|c|c|c|c|c|c|c|}
\hline Mechanism & Traffic accident & Fall & Motorcycle & Assault & Other mechanism & Total \\
\hline Frequency of any mechanism & 249 & 216 & 157 & 97 & 268 & 987 \\
\hline Frequency of surgical treatment & 128 & 71 & 72 & 42 & 111 & 424 \\
\hline Frequency of treatment without surgery & 121 & 145 & 85 & 55 & 157 & 563 \\
\hline
\end{tabular}

Table 6. Needs surgical treatment methods versus type of injury

\begin{tabular}{lll}
\hline Surgical & No. & \% \\
\hline Closed reduction of fracture without internal fixation & 31 & 7.31 \\
\hline Closed reduction of fracture with internal fixation & 12 & 2.8 \\
\hline Open reduction of fracture with internal fixation & 26 & 19 \\
\hline Internal fixation of bone without fracture reduction, other & 17 \\
\hline Exploratory laparotomy & 55 & 4.1 \\
\hline Fusion & 33 \\
\hline Suture of skin and subcutaneous tissue of other sites & 12.9 \\
\hline Repair of vertebral fracture & 7.78 \\
\hline Incision of abdominal wall & 4.24 \\
\hline Other exploration and decompression of spinal canal & 12 \\
\hline Catheterization & 33 \\
\hline Other surgical procedures & 2.83 \\
\hline Total & 40 \\
\hline
\end{tabular}

revealed that male injuries were more than female injuries (10). Another study by Karbakhsh et al in Kermanshah (11) showed that $78.6 \%$ of TSI patients were males. The male to female ratio was 3.66. The mean age of patients was 34.7 years with a median of 28 years. Also in other study whit title of spinal fractures resulting from traumatic injuries that has been done in Iran has been express that of all patients that studied, $68.5 \%$ were males. The peak (maximum) frequency of the mentioned injuries was occurred in the 21 to 40 -year age-group (5).

Concerning the education level, $63 \%$ of cases were under diploma and $16 \%$ had a university degree. In the study conducted by Karbakhsh et al in Kermanshah in 2009, similar results were obtained. In their study, $31.4 \%$ of patients were illiterate and $20.5 \%$ had only primary education. Only $2.6 \%$ of patients had university education (11). Education level plays a role in which the lower the education level, the more the probability of trauma. Also, trauma was more common in unemployed people (11). Regarding the patients suffering from TSI, most of them respectively were workers (27.35\%), and unemployed (25.53\%), housewives $(16.21 \%)$ or students $(17.73 \%)$, and others had different jobs or their jobs were not specified. Because it reflects lack of income and insecurity, unemployment has been used as an indicator of material deprivation and this underlie for trauma. The higher number of workers in this study can be related to that Kashan is an industrial city and have many workers that lives in Kashan, therefore, the incidence of trauma is more in this city and in this group of people (12).

Injuries were more common between late spring until the end of September (76.9\%). Karbakhsh et al reported that about $17.5 \%$ of patients referred to the hospital on holidays (11). In a study in India findings showed that two-thirds of RTAs occurred during the leisure time on Fridays/ Saturdays and Sundays (13). Summer had the highest rate for all types of RTAs. Thirty one percent of fatal accidents and $29.6 \%$ of injuries occurred during the summer (14). In this study more rate of injury was happening between spring and summer, this can be because that more rate of travel also traffics accidents that could been in this time and in result more case of all type of trauma and TSI.

The most common cause of TSI in the age group of 15 to 30 years was motorcycle accident, followed by assault. But car accident and fall were the most common cause of spinal injury. (Table 2). Falls and motor vehicle 
accidents accounted for approximately equal numbers of spinal injury. This finding is in line with others studies. Karbakhsh et al (11) reported that victims of RTA (53.5\%) and falls $(28.8 \%)$ included the highest proportion of cases of TSI, followed by interpersonal violence (10.1\%). Yousefzadeh et al (15) report that the most common cause of spinal injuries were motor vehicle accidents (52\%) and falls $(43 \%)$. The rest were due to the fall of a heavy object on spine $(2.4 \%)$ and other mechanism were $(2.4 \%)$.

TSI due to fall appeared to be predominant Cause in developing countries (16). Research findings show that falls are the most common cause of spinal injury, while motor vehicle injuries are the second $(16,17)$. This may not be the case for a developing country like Iran in which a high rate of injuries is related to RTAs $(18,19)$. Evidence shows that there is a great difference in the prevalence of various causes of traumatic injuries between developed and developing countries (20).

In Europe, the most common cause of traumatic spinal injuries are traffic accidents (10,21). In a study in Norway (22), falls were the most common cause. Ning et al reported motor vehicle crashes and falls as the main causes of injury in Asia and the latter is on a rise (23). In underdeveloped countries, the use of motor vehicle is not as common as in North America and Europe (23). Different lifestyle and different regions within a country play a role in the mechanism of trauma (5). Fakharian et al (9) showed that car accident composed $29.9 \%$ of all traumatic spinal injuries.

Fracture of lumbar vertebra was the most common cause of traumatic spinal injury $(24.41 \%)$, but a study showed that TSI most common area was thoracolumbar spine fracture (46.9\%) such Yousefzadeh et al (15). that showed thoracolumbar spine was common area for fracture. Fakharian et al (9). Similar to result of This study, showed that lumbosacral spine was the most commonly involved region (64.8). Haidari et al reported that cervical spine fractures were can be significantly frequent in RTAs and lumbar fractures were are common in falls $(P<0.001)(5)$. In this study the rate of SCI was $2.63 \%$, in which 7 cases had thoracic spinal cord, 16 cases had cervical spinal cord and 3 cases had thoracolumbar SCI. Seventeen cases of SCI were due to RTAs and 4 cases were due to falls. The prevalence of traumatic SCI in Iran ranges from 1.2 to 11.4 per 10000 people (4). The global incidence of SCI varies from 8.0 to 246.0 cases per million inhabitants per year. During the years, there has been an increasing trend towards the prevalence rates of the regional differences regarding the prevalence rates of SCI across the globe (3). In researches conducted in Iran, cervical spine trauma was mostly seen in spinal cord injuries (60\%). similar results of this study, Fakharian et al resulted that the most of common cause of the SCI was cervical spine trauma (34\%), due to motor vehicle accidents (24). But in North America, the cervical spine trauma (55\%) is the most common anatomic region for SCI $(2,23,25-27)$.
The duration of hospital stay for all patients with TSI in this study was different in depended to age, sex and mechanisms and type of injury also extremely affected in surgery operation $(P=0.01)$. However, the median duration of hospital stay for all patients was 4 days (mean $=5.7)$. Patients with traffic accident injury had the most duration of hospital stay and the second long hospitalization was for falls and assaultation. Result of this study in field was Similar to study of Haidari et al (5). The median duration of hospital stay for all patients with TSI was 4 days and the length of hospitalization was not significantly different between the two major mechanisms of spine injury $(P=0.345)$.

Among 986 patients with TSI, $34.8 \%$ had multi-regional injury. Head injuries were the most common injuries and also the most frequent among the lesions leading to hospitalization. Clayton et al (26) has performed an study in the United States to report that the pelvic fracture and head injury may have a greater effect than the multiplicative interaction which is high risk for cervical spine injury. Similar the results of the presented study, Fakharian et al showed that the head and face injuries are the most common injuries attendant with TSI (24).

Totally, $97.7 \%$ of patients survived, but $2.3 \%$ died in the hospital and two patients died later. Patients with spine injury as a result of car accident had a significantly higher rate of death in comparison to those who were injured by falling $(1.5 \%$ vs $0.5 \%, P=0.04)$. In Study of Haidari et al, out of the total patients with spinal fractures $96 \%$ survived (5). Patients with spinal fractures as a result of RTAs had a significantly higher rate of death than those who were injured due to falling.

\section{Conclusion}

This study has found that the most common causes of spinal injury in Kashan are traffic accidents and fall and prevention with traffic rules and transport safety. Also, work and life environments can be effective in reducing spinal cord injuries. Due to the expensive costs for patients and health care system so prevention and education are effective in diminishing of injuries. More detailed information about the causes of the spinal injury should be noted, based on in-depth investigation, as it might lead to a more target intervention.

\section{Limitations}

This study was done retrospectively. Use of a database of hospital could have caused potential confounding and undetected bias in results. Missing of some information into the study databases may have skewed results.

\section{Ethical issues}

This study was approved by the ethics committee of Kashan University of Medical Science with code number 96146. 


\section{Authors' contribution}

Methodology: EF, ZS, MS. Analysis: EF, ZS, MS. Resources: ZS.Writing-Review \& Editing: EF, ZS, MS. Supervision: EF

\section{Acknowledgments}

We express our thanks to the Research Center for Trauma and orthopedics as well as Neurosurgery physicians of Shahid Beheshti Hospital of Kashan.

\section{References}

1. Moradi-Lakeh M, Rasouli MR, Vaccaro AR, Saadat S, Zarei MR, Rahimi-Movaghar V. Burden of traumatic spine fractures in Tehran, Iran. BMC Public Health 2011; 11: 789. doi: 10.1186/1471-2458-11-789.

2. Haddadi K, Yousefzadeh F. Epidemiology of Traumatic Spinal Injury in north of Iran: a prospective Study. Iran J Neurosurg 2016; 1(4): 11-4. doi: 10.18869/acadpub. irjns.1.4.11.

3. Rahimi-Movaghar V, Saadat S, Rasouli MR, Ganji S, Ghahramani M, Zarei MR, et al. Prevalence of spinal cord injury in Tehran, Iran. J Spinal Cord Med 2009; 32(4): 42831. doi: 10.1080/10790268.2009.11754572.

4. Furlan JC, Sakakibara BM, Miller WC, Krassioukov AV. Global incidence and prevalence of traumatic spinal cord injury. Can J Neurol Sci 2013; 40(4): 456-64.

5. Heidari P, Zarei MR, Rasouli MR, Vaccaro AR, RahimiMovaghar V. Spinal fractures resulting from traumatic injuries. Chin J Traumatol 2010; 13(1): 3-9.

6. Lee BB, Cripps RA, Fitzharris M, Wing PC. The global map for traumatic spinal cord injury epidemiology: update 2011, global incidence rate. Spinal Cord 2014; 52(2): 110-6. doi: $10.1038 /$ sc.2012.158.

7. Ackery A, Tator C, Krassioukov A. A global perspective on spinal cord injury epidemiology. J Neurotrauma 2004; 21(10): 1355-70. doi: 10.1089/neu.2004.21.1355.

8. Rasouli MR, Nouri M, Rahimi-Movaghar V. Spinal cord injuries from road traffic crashes in southeastern Iran. Chin J Traumatol 2007; 10(6): 323-6.

9. Fakharian E, Mohammadzadeh M, Saberi HR, Fazel MR, Rejali M, Akbari H, et al. Spinal injury resulting from car accident: focus to prevention. Asian J Neurosurg 2017; 12(2): 180-4. doi: 10.4103/1793-5482.152110.

10. Knutsdottir S, Thorisdottir H, Sigvaldason K, Jonsson $H$ Jr, Bjornsson A, Ingvarsson P. Epidemiology of traumatic spinal cord injuries in Iceland from 1975 to 2009. Spinal Cord 2012; 50(2): 123-6. doi: 10.1038/sc.2011.105.

11. Karbakhsh M, Zandi NS, Rouzrokh M, Zarei MR. Injury epidemiology in Kermanshah: the National Trauma Project in Islamic Republic of Iran. East Mediterr Health J 2009; 15(1): 57-64.

12. Davoodabadi A, Yazdani AR, Sayyah M, Mirzadeh Javaheri M. Trauma epidemiology and its consequences in victims referred to Kashan Trauma Center during 2007-8. Feyz Journal of Kashan University of Medical Sciences 2011; 14(5): 500-5.

13. Gopaul CD, Singh-Gopaul A, Sutherland JM, Rostant L,
Ebi KL, Chadee DD. The epidemiology of fatal road traffic Collisions in Trinidad and Tobago, West Indies (20002011). Glob Health Action 2016; 9: 32518. doi: 10.3402/ gha.v9.32518.

14. Khorshidi A, Ainy E, Hashemi Nazari SS, Soori H. Temporal patterns of road traffic injuries in Iran. Arch Trauma Res 2016; 5(2): e27894. doi: 10.5812/atr.27894.

15. Yousefzadeh Chabok S, Safaee M, Alizadeh A, Ahmadi Dafchahi M, Taghinnejadi O, Koochakinejad L. Epidemiology of traumatic spinal injury: a descriptive study. Acta Med Iran 2010; 48(5): 308-11.

16. Wang H, Zhang Y, Xiang Q, Wang X, Li C, Xiong H, et al. Epidemiology of traumatic spinal fractures: experience from medical university-affiliated hospitals in Chongqing, China, 2001-2010. J Neurosurg Spine 2012; 17(5): 459-68. doi: 10.3171/2012.8.spine111003.

17. Zargar M, Karbakhsh M, Zarei MR, Moez Ardalan K. Patterns of assault: experience from an urban hospitalbased study in a developing country. Iran Red Crescent Med J 2004; 6(2): 50-4.

18. Zargar M, Modaghegh MH, Rezaishiraz H. Urban injuries in Tehran: demography of trauma patients and evaluation of trauma care. Injury 2001; 32(8): 613-7.

19. Moini M, Rezaishiraz H, Zafarghandi MR. Characteristics and outcome of injured patients treated in urban trauma centers in Iran. J Trauma 2000; 48(3): 503-7.

20. Modaghegh MH, Roudsari BS, Sajadehchi A. Prehospital trauma care in Tehran: potential areas for improvement. Prehosp Emerg Care 2002; 6(2): 218-23.

21. Amin A, Bernard J, Nadarajah R, Davies N, Gow F, Tucker S. Spinal injuries admitted to a specialist centre over a 5-year period: a study to evaluate delayed admission. Spinal Cord 2005; 43(7): 434-7. doi: 10.1038/sj.sc.3101734.

22. Hagen EM, Eide GE, Rekand T, Gilhus NE, Gronning M. A 50-year follow-up of the incidence of traumatic spinal cord injuries in Western Norway. Spinal Cord 2010; 48(4): 313-8. doi: 10.1038/sc.2009.133.

23. Ning GZ, Wu Q, Li YL, Feng SQ. Epidemiology of traumatic spinal cord injury in Asia: a systematic review. J Spinal Cord Med 2012; 35(4): 229-39. doi: 10.1179/2045772312y.0000000021.

24. Fakharian E, Tabesh H, Masoud SA. An epidemiologic study on spinal injuries in Kashan. Journal of Guilan University of Medical Sciences 2004; 13(49): 79-85. [In Persian].

25. Saadat S, Eghbali A, Vaccaro AR, Sharif-Alhoseini M, Rahimi-Movaghar V. Blunt traumatic cervical spine fractures in Iran. Surg Sci 2011; 2(8): 407-13. doi: 10.4236/ ss.2011.28089.

26. Clayton JL, Harris MB, Weintraub SL, Marr AB, Timmer J, Stuke LE, et al. Risk factors for cervical spine injury. Injury 2012; 43(4): 431-5. doi: 10.1016/j.injury.2011.06.022.

27. Fazel MR, Fakharian E, Mahdian M, Mohammadzadeh M, Salehfard L, Ramezani M. Demographic profiles of adult trauma during a 5 year period (2007-2011) in Kashan, IR Iran. Arch Trauma Res 2012; 1(2): 63-6. doi: 10.5812/ atr.6770. 